



\section{Boletín del Museo Chileno de Arte Precolombino}

VOLUMEN 17 | NÚMERO 2

Santiago, 2012

ARQUEOMETRÍA DE PIGMENTOS:

CASOS ARQUEOLÓGICOS Y PROTOCOLOS

DE INVESTIGACIÓN

Editores asociados para este número

Mariel A. López

Guillermo A. de la Fuente

Dánae Fiore 



\section{Contenido}

\section{9-10 Presentación \\ Foreword}

11-25 Variabilidad en la utilización de pigmentos en entierros humanos del Holoceno Tardío en la cuenca superior del río Santa Cruz (Patagonia Argentina) Variability in the use of pigments in Late Holocene burials in the upper Santa Cruz river basin (Argentine Patagonia)

Nora Viviana Franco, Ana Lucía Guarido, Teresita Montenegro \& Pablo Ambrústolo

27-38 Evidencias químicas de deterioro ambiental en manifestaciones rupestres: Un caso de estudio del oeste tinogasteño (Catamarca, Argentina)

Chemical evidence of environmental deterioration in rock art: A case study in western Tinogasta (Catamarca, Argentina)

Eugenia Tomasini, Mara Basile, Norma Ratto \& Marta Maier

39-51 Estudio de pigmentos en alfarería Estilo Negro sobre Rojo de Quebrada de Humahuaca, Jujuy, Argentina

Study of pigments used in Black-on-Red ceramics from Quebrada de Humahuaca, Jujuy, Argentina

Verónica J. Acevedo, Mariel A. López, Eleonora Freire, Emilia B. Halac, Griselda Polla \& María Reinoso

53-64 Técnicas arqueométricas combinadas aplicadas al análisis de diseños de alfarería "tricolor" de Quebrada de Humahuaca, Jujuy, Argentina

Combined archaeometric techniques applied to the analysis of "tri-color" ceramic designs from Quebrada de Humahuaca, Jujuy, Argentina

Fernando Marte, Verónica J. Acevedo \& Noemí Mastrangelo

65-74 Empleo de espectroscopia Raman, difracción de rayos $X$ y microscopia electrónica para el análisis de pigmentos en cerámicas Vaquerías

The use of Raman spectroscopy, X-ray diffraction and electron microscopy in the analysis of pigments from Vaquerías ceramics

M. Fabiana Bugliani, Claudia Di Lello, Eleonora Freire, Griselda Polla, Alicia Petragalli, María Reinoso \& Emilia B. Halac

75-81 Arqueometría del arte: Estudios fisicoquímicos de pigmentos arqueológicos Archaeometry of art: Physical and chemical studies of archaeological pigments Mariel A. López, Guillermo A. de la Fuente \& Dánae Fiore 



\section{In Memoriam}

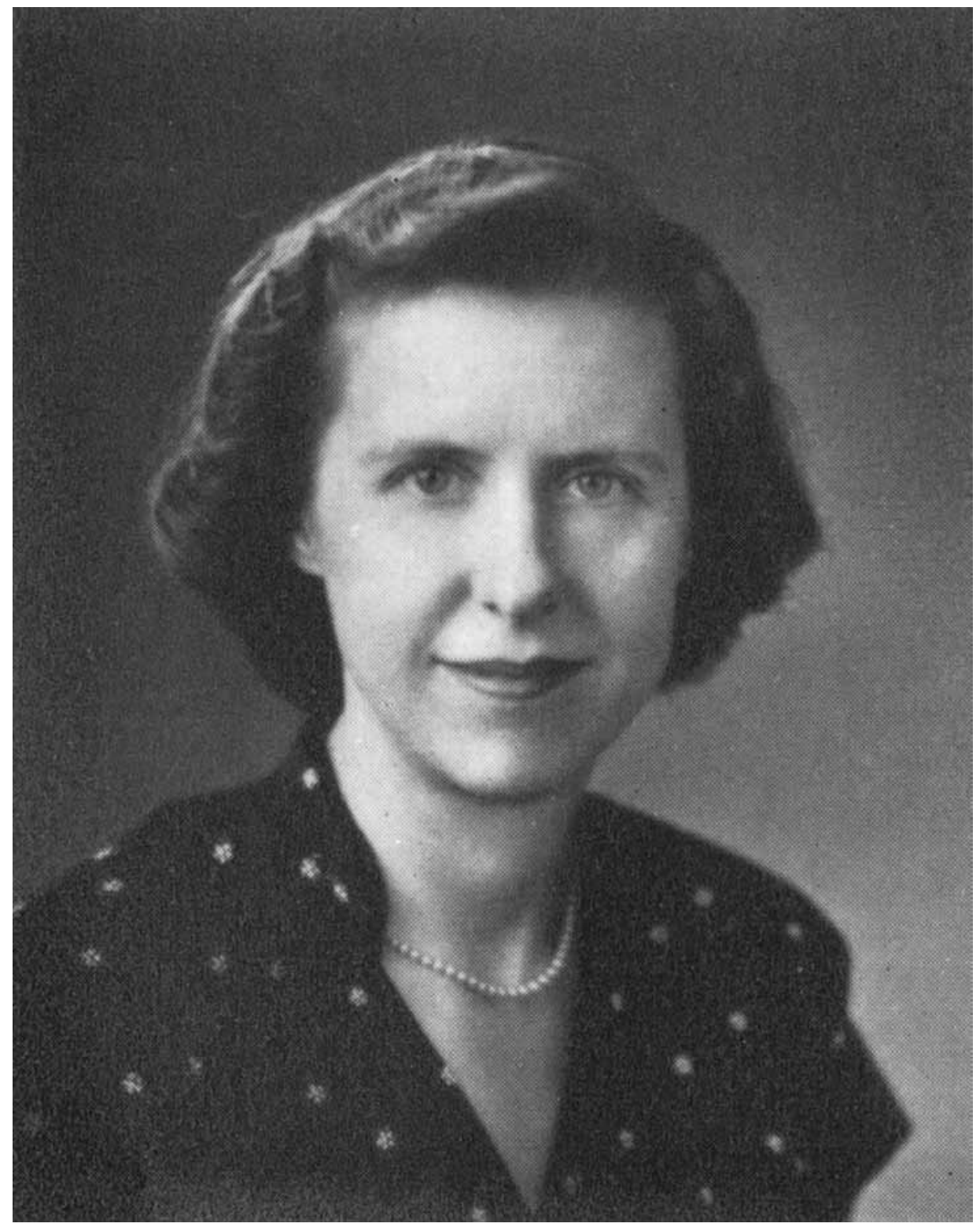

Betty J. Meggers

(1921-2012) 



\section{Presentación}

En este número se reúnen algunos de los trabajos presentados en el simposio "Arqueometría de pigmentos: Casos arqueológicos y protocolos de investigación" que se desarrolló en el marco del IV Congreso Nacional de Arqueometría Argentina entre los días 8 y 11 de noviembre de 2011 en la ciudad de Luján, provincia de Buenos Aires. El mismo constituyó la continuación de un encuentro anterior, celebrado durante el XVII Congreso Nacional de Arqueología Argentina en el año 2010 en la ciudad de Mendoza. Fue un punto de reunión enriquecedor con los colegas especialistas en este tema, de los cuales se incluyen cinco trabajos en este volumen del Boletín del Museo Chileno de Arte Precolombino. A todos ellos y muy especialmente al relator de este último simposio, Ingeniero Químico Fernando D. Marte, y los editores de esta revista, el Dr. José Berenguer y la Lic. Andrea Torres, les agradecemos la posibilidad de contribuir con esta publicación.

En los últimos años en la arqueología argentina se ha visto un incremento en los estudios relacionados con la caracterización de materiales arqueológicos mediante la investigación interdisciplinaria. Básicamente, estos estudios se han realizado a partir de la incorporación y la utilización de diversas técnicas analíticas procedentes de las ciencias fisicoquímicas para resolver problemas arqueológicos específicos.

Los trabajos presentados en este volumen son una prueba de la utilización complementaria de diferentes técnicas analíticas al estudio de pigmentos arqueológicos en diferentes soportes. El trabajo de Franco, Guarido, Montenegro y Ambrústolo analiza el uso de pigmentos en los sitios Río Bote 1 y Huyliche 1 (Provincia de Santa Cruz, Patagonia Argentina) para evaluar si existieron cambios en el uso de dichos materiales entre el 3740 AP (fecha del primer sitio) y el 430 AP (fecha del segundo). El de Tomasini, Basile y Ratto estudia la preservación de imágenes rupestres pintadas en Cueva de La Salamanca (Provincia de Catamarca, Noroeste Argentino) para mostrar de qué modo inciden los factores naturales y antrópicos en la alteración y el deterioro de las pinturas.

El manuscrito de Acevedo, López, Freire, Halac, Polla y Reinoso analiza los pigmentos de la alfarería del Estilo Negro sobre Rojo del sitio Pintoscayoc 1, Período de Desarrollos Regionales (ca. 1000-1480 DC) (Provincia de Jujuy, Noroeste Argentino) para interpretar cuáles podrían haber sido los precursores de esos colores y su naturaleza, planteando nuevas interrogantes en 
torno a la tecnología de la cocción de la cerámica. El trabajo de Marte, Acevedo y Mastrangelo estudia las características pigmentarias de la cerámica del Estilo Negro y Blanco sobre Rojo del sitio Pintoscayoc 1 para definir las características generales de la ejecución del proceso de pintado y posibles repintes de las superficies cerámicas. El de Bugliani, Di Lello, Freire, Polla, Petragalli, Reinoso y Halac analiza los pigmentos rojo y negro de materiales cerámicos del Período Formativo (300 AC-900 DC), Estilo Vaquerías procedente de los sitios Cardonal y Bordo Marcial (Provincia de Catamarca, Argentina) para determinar su composición y forma de aplicación. Finalmente, un trabajo de síntesis por los compiladores de este volumen presenta una historia compendiada de las investigaciones arqueométricas sobre pigmentos, una evaluación bibliométrica de las publicaciones de congresos en Argentina respecto de este tema -insertada en dicho contexto-, para luego pasar a la presentación comparativa de los trabajos que constituyen esta edición.

La suma de estos seis artículos aporta entonces un conjunto cuya lectura ofrece información sobre el uso del color abarcando un interesante rango de casos, desde cazadores-recolectores que emplearon pigmentos en la producción de arte rupestre y en inhumaciones de personas, hasta poblaciones sedentarias que los utilizaron en la producción de alfarería. Asimismo, este volumen ofrece un valioso espectro de técnicas de laboratorio, que le permitirán al lector adentrarse en los alcances y las potencialidades de cada una de ellas.

Tal como demuestran estos trabajos, el uso del color ha estado presente en muy diversas formas en la vida cotidiana y ceremonial de los grupos humanos del pasado remoto y reciente: su abordaje mediante el análisis de pequeñas muestras arqueológicas permite adentrarnos en las cualidades naturales, tecnológicas e incluso simbólicas subyacentes a estos mundos visuales del pasado.

Mariel Alejandra López Guillermo Adrián de la Fuente Dánae Fiore 